\title{
Statistical Downscaling of Daily Temperature and Rainfall Data from Global Circulation Models, in Borkena River Catchment, Ethiopia
}

\author{
Kasye Shitu ${ }^{1}$, Shimelis Berhanu ${ }^{2}$ \\ ${ }^{1}$ Department of Soil and Water Resource Management, Assosa University, Assosa, Ethiopia \\ ${ }^{2}$ School of Water Resource and Environmental Engineering, Haramaya Institute of Technology, Haramaya University, Haramaya, Ethiopia
}

Email address:

kasye61921@gmai.com (K. Shitu), shimelisberhanu@yahoo.com (S. Berhanu)

To cite this article:

Kasye Shitu, Shimelis Berhanu. Statistical Downscaling of Daily Temperature and Rainfall Data from Global Circulation Models, in Borkena River Catchment, Ethiopia. Journal of Water Resources and Ocean Science. Vol. 9, No. 5, 2020, pp. 87-97.

doi: $10.11648 /$ j.wros.20200905.11

Received: February 18, 2020; Accepted: March 3, 2020; Published: September 24, 2020

\begin{abstract}
Statistical downscaling models for temperature and precipitation in Borkena River Catchment, have been developed and applied to calculate the changes in historic, current and future climate changes. Projected changes in precipitation and temperature were analyzed using the outputs from GCMs and stations data (1976-2005) which were collected from 4 observed meteorological stations (predictand) and downscaling using SDSM version 4.2.9a. The study investigated how these changes in temperature and precipitation might translate into changes in livelihoods of people and other biophysical components using impact assessments. The objective of this paper was to evaluate the statistical downscaling methods in estimating monthly average rainfall and temperature, in line with this it was also conducted to project the future climate situation of Borkena River catchment (Ethiopia). Accordingly, the results revealed that both temperatures (maximum and minimum) showed an increasing trend. The result of future temperature from SDSM for RCP4.5 and RCP8.5 show increased rate on annual basis except 202s for RCP4.5. The maximum increasing value will occur for RCP8.5 in the 2020s and 2080s with a value of $1.85^{\circ} \mathrm{C}$ and $2.82^{\circ} \mathrm{C}$ for minimum and maximum temperature respectively. Downscaled precipitation results of future time interval of this study indicated decreased precipitation value for both RCP4.5 and RCP8.5 on annual basis. This, may increase water availability stresses in the study area. Therefore, this facilitate the decision makers to incorporate climate change scenarios for devising sustainable strategies, including: water harvesting technologies, supplementary irrigation, using improved seeds, which can tolerate moisture stresses, afforestation and reforestation programs, and soil and water conservation techniques. Moreover, crop diversifications, agricultural extension services access, related strategies, and measures are highly recommended for climate change resiliencies.
\end{abstract}

Keywords: Borkena, River Catchment, Statistical Downscaling, GCM and CanESM2

\section{Introduction}

Scientists have reached a consensus that the global annual average temperature is likely to be $2^{\circ} \mathrm{C}$ above pre-industrial levels by 2050 , and a $2^{\circ} \mathrm{C}$ warmer world will experience more intense rainfall and more frequent and more intense droughts, floods, heat waves, and other extreme weather events which poses significant economic and environmental risks in worldwide [1].

According to IPPC [2] one of the major impacts of climate change phenomenon is on local water resource availability, whose impact will be felt by many sectors, including agriculture; climate change also will have a profound impact on the availability and variability of fresh water as the frequency of climatic extremes such as heat waves, drought, and change in rainfall pattern increases in response to global warming [3]. So, now a time the need for climate change information at the regional to local scale is one of the central issues within the global change debate. Such information is necessary in order to assess the impacts of climate change on human and natural systems and to develop suitable adaptation and mitigation strategies at the national level for 
future time [1].

Studies for future climate change by using a hierarchy of coupled ocean/atmosphere/sea-ice/land-surface models to provide indicators of global response as well as possible regional patterns of climate change was conducted by [4] and Climate change scenario was obtained from GCM of the World Climate Research Programs Coupled Model of Intercomparison Project Phase5 (CMIP5) multi model data set [4].

In Ethiopia, we have explored various downscaling applications and their potential to detect climate change impacts in agricultural and hydrological applications. Some of these applications include statistical downscaling for daily temperature and rainfall in South Wollo [5], the study of future changes in climate parameters in Amhara Regional State [6]. impact of climate change on streamflow hydrology in headwater catchments of the upper Blue Nile Basin, Ethiopia [7]. However, applications of statistical downscaling of general circulation models for Borkena River Catchment, Awash River Basin, in Ethiopia have not been undertaken. Due to this statistical downscaling model for daily temperature and precipitation in Borkena River Catchment, Awash River Basin, Ethiopia, have been developed and applied to calculate the changes in the future climate changes due to projected changes in the atmospheric composition based on the objectives of evaluating statistical downscaling methods in estimating monthly average rainfall and temperature at weather stations of Borkena River Catchment and projection of future climate situation of Borkena River Catchment.

\section{Materials and Methods}

\subsection{Location}

The study was conducted in Borkena River catchment, Awash River Basin, Ethiopia, which is located at $10^{\circ} 36^{\prime} 0^{\prime \prime}$ $11^{\circ} 24^{\prime} 0 " \mathrm{~N}$ latitude and $39^{\circ} 24^{\prime} 00^{\prime \prime}-40^{\circ} 12^{\prime} 0$ ' E longitudes. The total area and the longest flow path towards the outlet of Borkena River catchment is $1,260 \mathrm{~km}^{2}$ and $85 \mathrm{~km}$ respectively which obtained from the DEM delineation of the River catchment. It is one of the main tributaries of the Awash River and originated from mountainous chains and escapements found in the Northern plateau at an elevation of $3,408 \mathrm{~m}$ a. s. 1 and drains to adjacent of Afar, Rift Valley down to Southeastern direction at an elevation of 1,427 $\mathrm{m}$ a. s. 1.

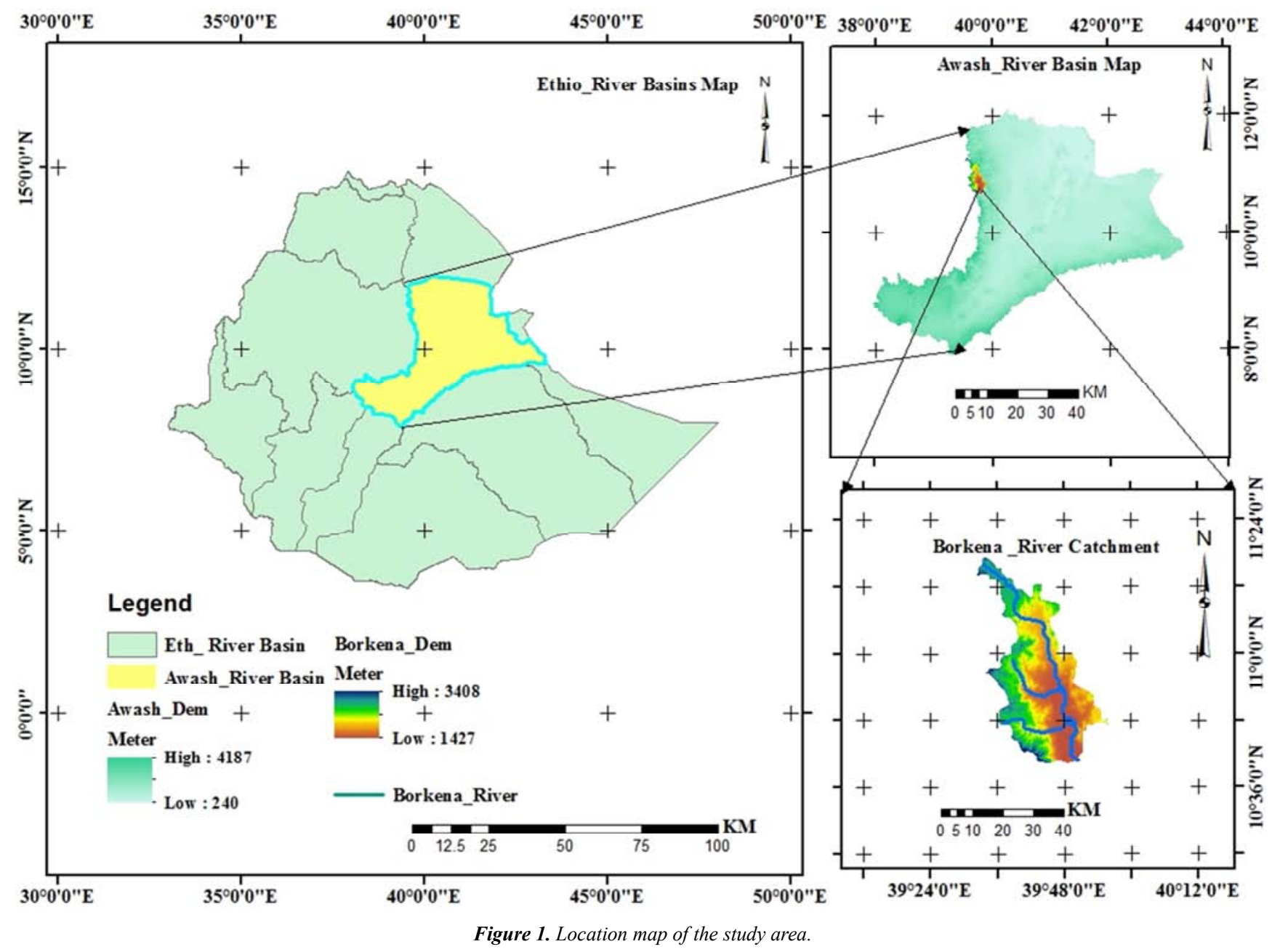




\subsection{Data Collection Methods}

Thirty year's observed rainfall and temperature data (1976-2005) were collected from National Meteorological Agency (NMA) of Ethiopia from 4 meteorological stations in and around the River catchment. The GCM data were collected from canESM2 general circulation model which was freely available at the Canadian climate change scenario group website (http://climate scenarios.canada.ca/?page $=$ dstsdi) for the African windows. Form this by using Statistical Downscaling Method (SDSM) data were downscaled to the site level. The model results were available for both RCP4.5 and RCP8.5 emission scenarios and the results were used to produce the expected future rainfall and temperature of the study area in order to study their variability in the future.

SDSM was used SDSM4.2.9a decision support tool which was downloaded from https://www.sdsm.org.uk/ for the assessment of regional climate change impacts. This decision support tool was developed by Wilby and Dawson in 2007 [8] and used to downscale large predictors. In this study during statistical downscaling process screen variable operation was done after a quality control check and transformation of rainfall data by fourth root were conducted. Identifying the best predictors was done on the relationship which was drawn between a suite of global scale predictors and local scale predictand, based on linear correlation analysis and scatter plots; and finally the predictors with the highest correlation were selected.

\subsection{Downscaling the GCM Output}

The spatial resolution of canESM2 GCMs is too coarse ( $2.8^{\circ}$ latitude and $2.8^{\circ}$ longitude) so, to resolve important subgrid scale raw output data of climate change experiments from this General Circulation Models (GCMs) with an adequate basis for assessing the effects of climate change on landsurface processes at regional scales downscaling of this GCM is required [8]. So, the GCM data of canESM2 were downscaled with appropriate downscaling method which is called Statistical Downscaling Method (SDSM) to generate future representative data of the study area. After this, result comparisons of observed and downscaled data, quality control, calibration and validation of SDS model, selection of predictor variables and scenario generations for the base period and for the future time period were discussed in the following section.

\subsection{Selection of Predictor Variables}

Selection of predictor for this study was conducted for Kombolcha station as shown in Table 1 which is located in the nearby latitude and longitude in the study area for canESM2 model. The number of selected predictors for all weather parameters (rainfall, maximum and minimum temperature) varies from four to five. The correlation (r) statistics and $p$-values were used to explain the strength of the relationship between the predictor and predicted. Predictor variables which have a high correlation value (r) and $0 \mathrm{p}$-values were selected.

\section{Results and Discussions}

Table 1. Selected predictor variables for Kombolcha and Kemisse stations.

\begin{tabular}{|c|c|c|c|c|c|c|c|}
\hline Predictor & Tmax & (R) & Tmin & (R) & Precipitation & (R) & Remark \\
\hline Ncepp1-fgl.dat & & -0.277 & & -0.353 & & 0.077 & \multirow{7}{*}{$\begin{array}{l}\mathrm{P} \text { valve is zero for } \\
\text { all parameters }\end{array}$} \\
\hline \multicolumn{8}{|l|}{ Ncepp1-ugl.dat } \\
\hline Ncepp1-vgl.dat & & -0.118 & & & & & \\
\hline Ncep500gl.dat & & 0.295 & & 0.203 & & 0.072 & \\
\hline Nceps500gl.dat & & & & & & 0.086 & \\
\hline Ncepp8thgl.dat & & -0.212 & & & & & \\
\hline Ncepp850gl.dat & & & & -0.11 & & 0.249 & \\
\hline Ncepshumgl.dat & & & & 0.369 & & 0.096 & \\
\hline
\end{tabular}

\subsection{Model Calibration and Weather Generation}

After the SDSM was calibrated for each parameter separately for the first 20 years (1976-1995) of observed data and predictor variables of NCEP reanalysis data sets, weather generation was done for the last 10 years (1996-2005) of observed data set; the mean result of simulated and observed data of all predictand data variations were determined. Figure 2 a shows the mean of simulated and observed precipitation data of this study. All most all months of the year have underestimated simulated results for precipitation (Figure 2a).
In the model, even the above variation was observed in related with a mean of observed and simulated mean rainfall data at the monthly level but, the value of coefficient of determination $\left(\mathrm{R}^{2}\right)$ in Figure 2 (b) which shows the overall association of observed and simulated data in the base time was 0.929. So, the overall agreements of the observed and simulated mean results were very good with, related to the coefficient of determination $\left(\mathrm{R}^{2}\right)$. This shows high variation and good agreement of observed data and SDSM. 

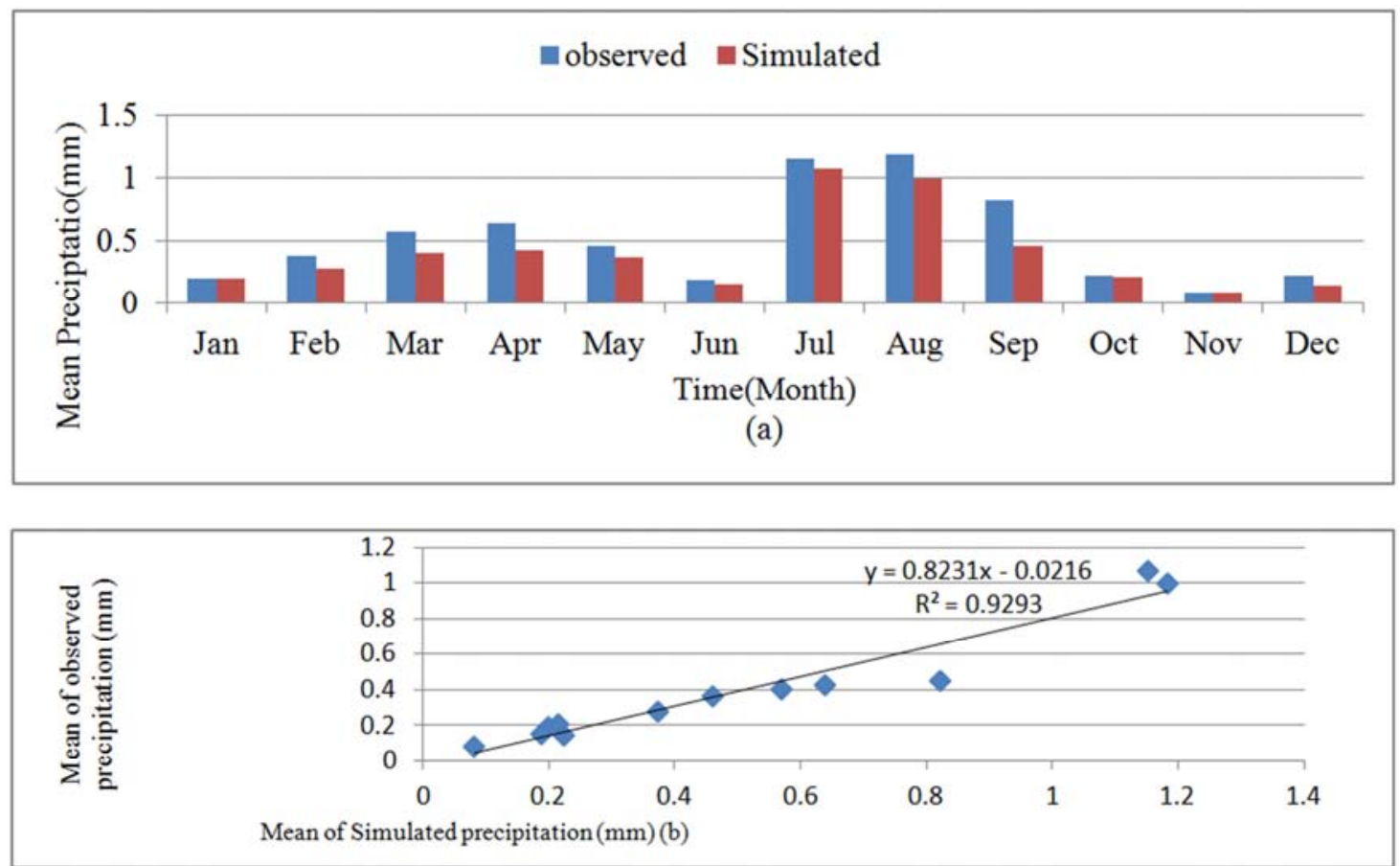

Figure 2. Simulated and observed mean daily precipitation (a) and $R^{2}$ (b) of Kombolcha station.

Similar to that of precipitation, the mean of observed and simulated maximum temperatures in this study show some variations in monthly level. However, the simulated mean maximum temperature graph superimposed on observed mean maximum temperature graph as it was indicated in Figure 3a. This shows that simulate and observed mean maximum temperature have all most equal means. In addition to mean of observed and simulated mean maximum temperature $\mathrm{R}^{2}$ value shows good relationship between the observed and simulated maximum temperature data of the study area (Figure 3b).
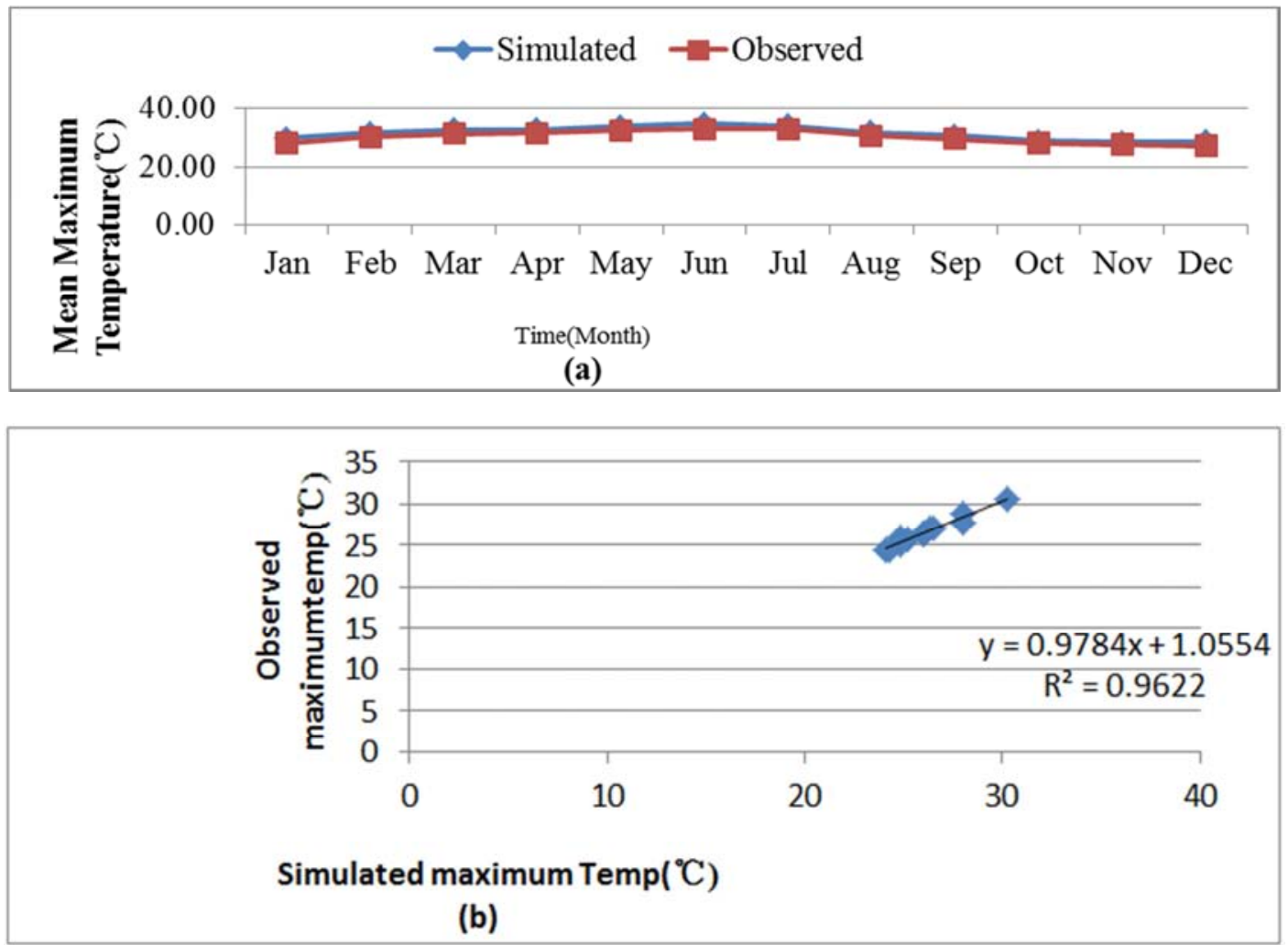

Figure 3. Simulated and observed mean daily maximum temperature (a) and $R 2$ (b) of Kombolcha station. 
The minimum temperatures of the River catchment have all most equal mean results like that of maximum temperature of the study area.

At the same time, $\mathrm{R}^{2}$ value shows the presence of great conformity between the observed and simulated mean minimum temperature data of the study area.
In this study from the three weather parameters (rainfall, maximum and minimum tempera), the SDSM model simulation result shows good performance related to the coefficient of determination for maximum temperature next to the minimum temperature.
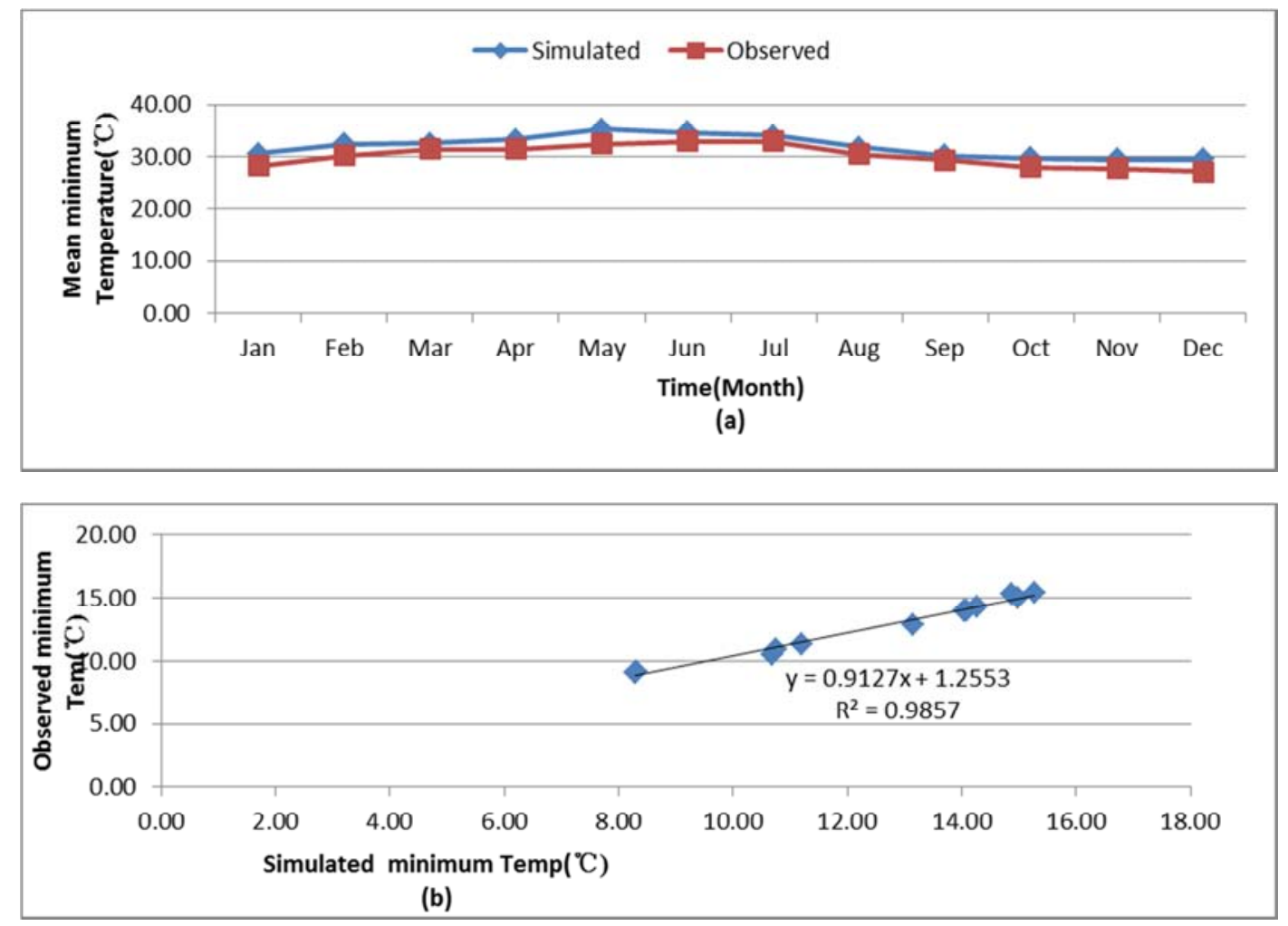

Figure 4. Simulated and observed mean daily minimum temperature (a) and R2 (b) Kombolcha station.

\subsection{Baseline Scenarios}

Baseline scenarios were performed for all weather data of this study (rainfall, maximum and minimum temperature) for the year 1976-2005. This used as a criterion for evaluating the performance of downscaling methods to identify whether the observed condition replicated in the method (SDSM) or not for the future time interval. For this CanESM2 GCM was downscaled for the baseline period (1976-2005) for the two climate change emission scenarios of representative concentration pathways (RCP4.5 and RCP 8.5). After this monthly mean of the downscaled data of this study were compared with monthly mean observed data of the study area. The means of the observed weather data (Tmin, Tmax and participation) comparison with the respective downscaled weather data of this study and absolute mode errors of downscaled monthly weather data were assessed in the following section.

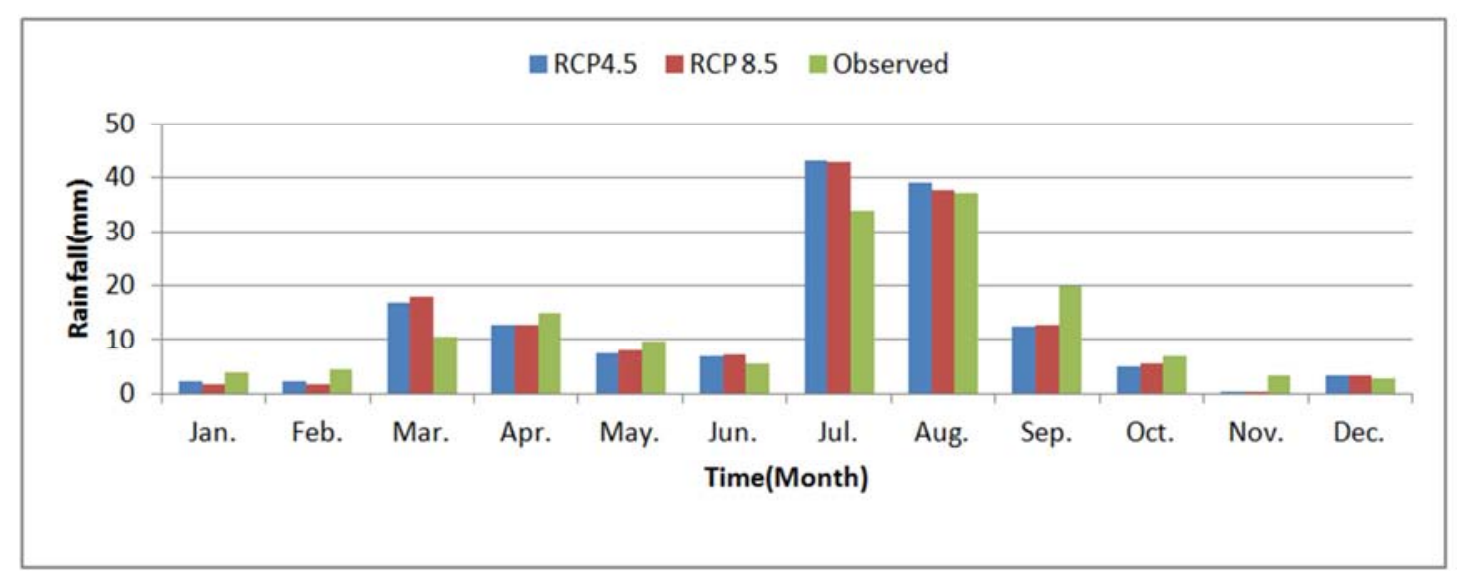

Figure 5. Mean monthly base time rainfall of the study area. 


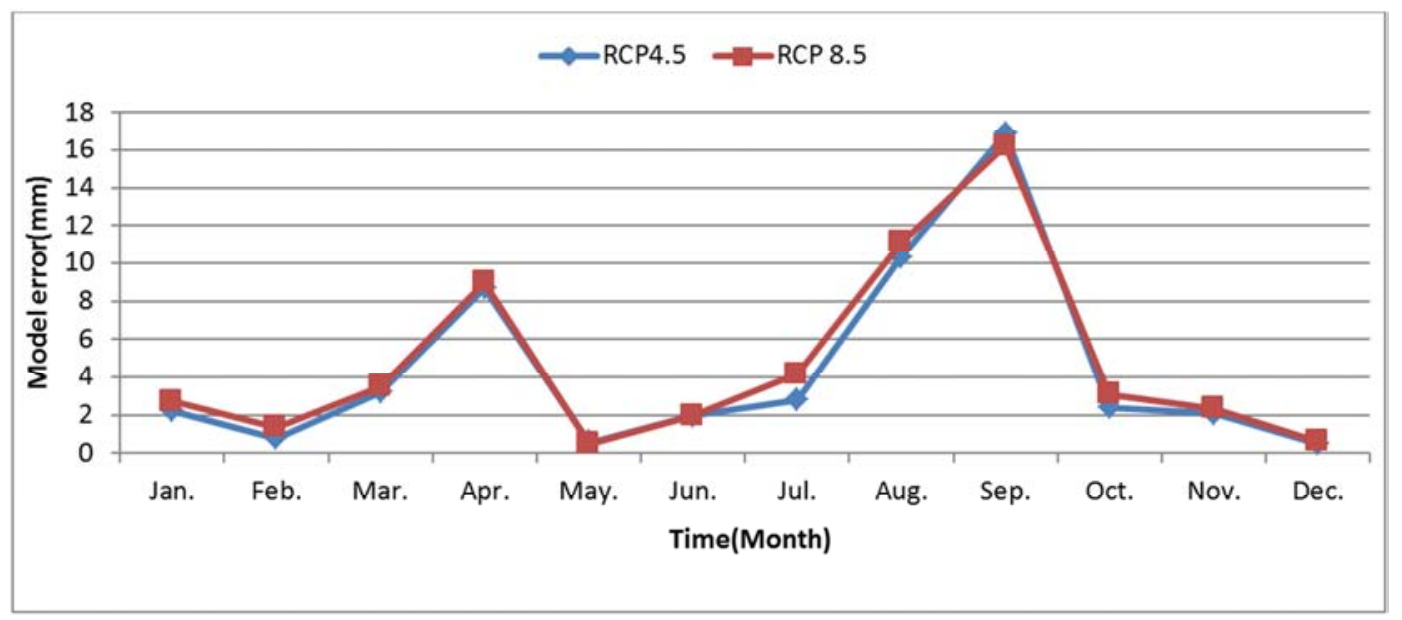

Figure 6. Absolute model errors of the study area for mean monthly base time rainfall.

\subsubsection{Precipitations}

The downscaled mean monthly precipitation data for both RCP4.5 and RCP8.5 of this study for a base line period were shown in Figure 5a. The Figures, indicted that the SDSM method has good performance in estimating the mean monthly precipitation in most months of the base period (1967-2005) for both RCP 4.5 and RCP8.5. However, due to non-parametric nature of rainfall, relative to temperature large absolute model error has occurred in some months of the year for both RCP4.5 and RCP8.5.
Absolute model errors (absolute value of the observed minus simulated data) in the estimation of mean daily precipitation for each month of the year in the baseline period of this study are shown in Figure 6. The result of absolute model errors indicates that large absolute model error was occurred in the month September, August and April.

In this study downscaled daily precipitation data for the base line period in the River catchment shows higher absolute model errors for RCP 8.5 emission scenario than that of RCP4.5 emission scenario in all months of the year.

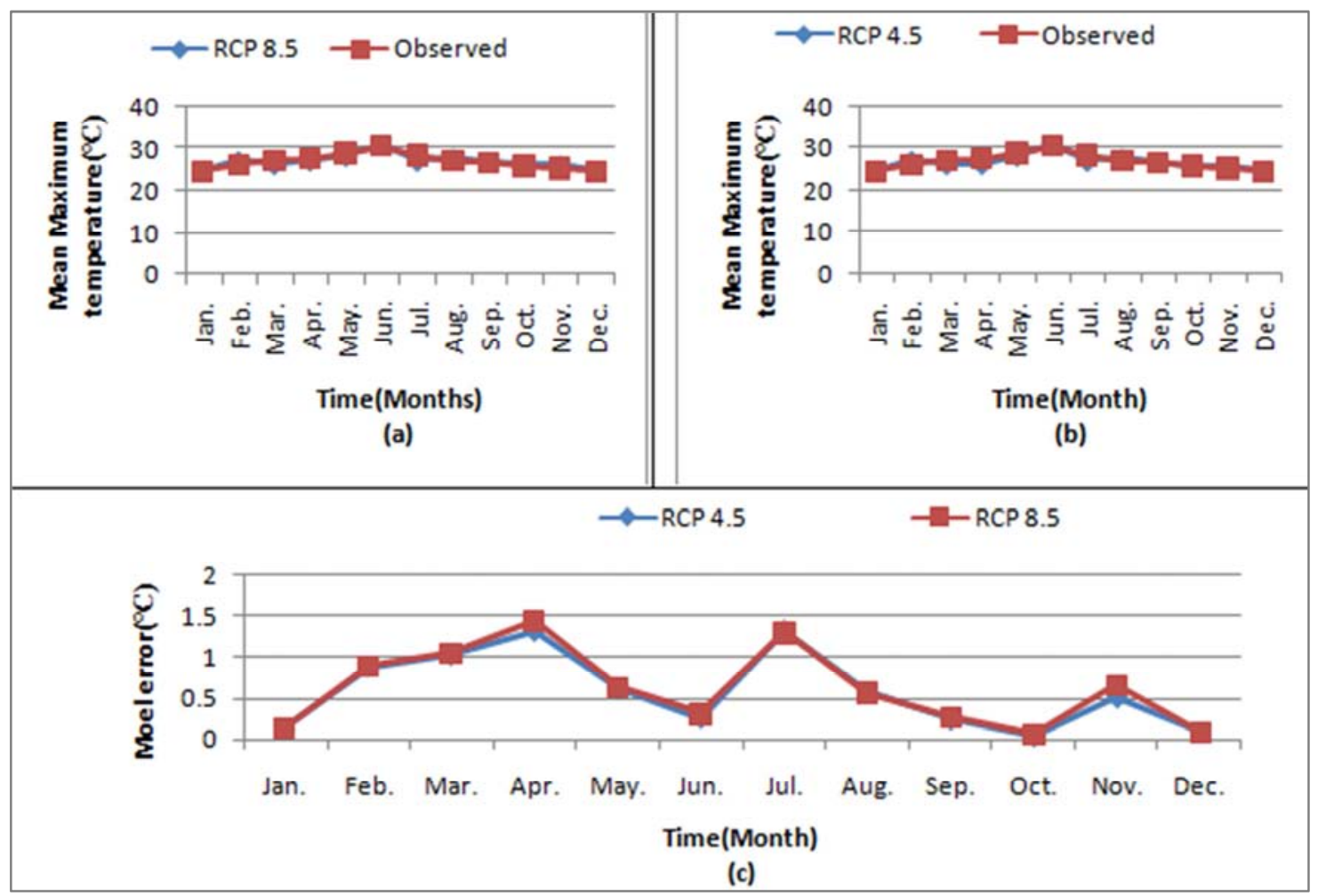

Figure 7. Mean monthly base time maximum temperature and model error of the study area.

\subsubsection{Maximum Temperature}

The maximum temperature which was downscaled for
RCP 4.5 and RCP 8.5 scenarios in the baseline period and the absolute model error of those scenarios in this study was shown in Figure 7 (, , b and c) respectively. In the baseline 
periods yet, the model error is different month to month in the River catchment, but for most of the time observed and downscaled mean monthly maximum temperature graphs are superimposed for most months of the year in the base time interval of this study. This shows that the similar nature of observed and downscaled base time maximum temperature for both RCP4.5 and RCP8.5 emission scenarios. And also, model error graph of both RCP4.5 and RCP8.5 are overlapped together in most case, as shown in Figure 7c. This may have occurred due to similarity nature of maximum temperature for both scenarios in the base period. On the other hand, as shown in Figure 7c months like July, April and March have a model error greater than $1^{\circ} \mathrm{C}$ and the reset months have a model error less than $1^{\circ} \mathrm{C}$.

In this study downscaling result of daily maximum temperature in baseline paired indicates higher value of absolute model errors for RCP 8.5 emission scenario than that of RCP4.5 emission scenario in all months. This may be occurred due to high emission of $\mathrm{CO}_{2}$ for RCP8.5 than that of RCP4.5.

\subsubsection{Minimum Temperature}

Graphs of observed and downscaled mean monthly minimum temperature in the base time have similar nature with a maximum mean monthly observed and downscaled temperature as show in Figure 8. In the River catchment like maximum temperatures and precipitations RCP 8.5 scenario has higher absolute model error than RCP 4.5 scenario in most cases for minimum temperature in the baseline period. Conversely, this point as compared to maximum temperature and precipitation the model error of minimum temperature is very low.

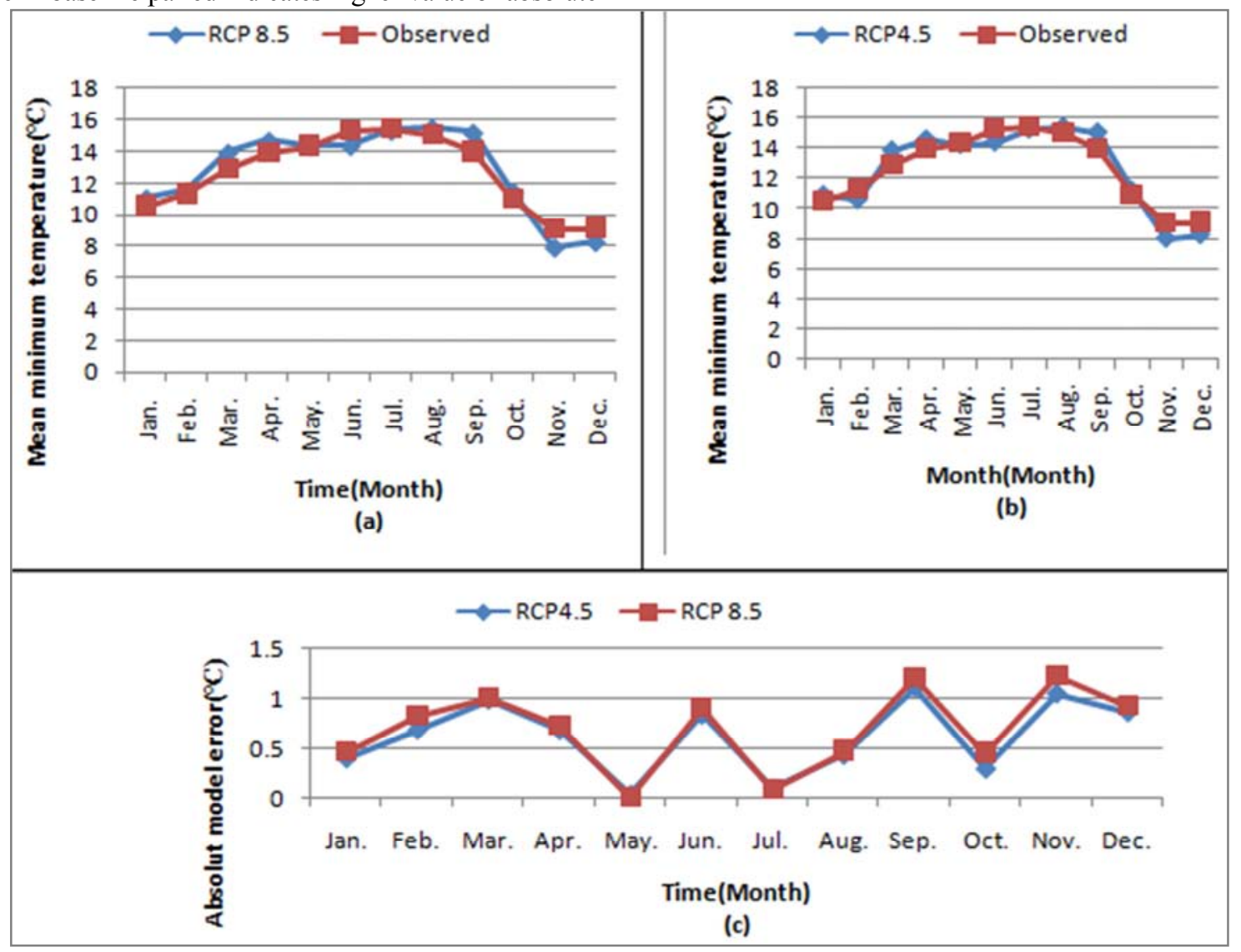

Figure 8. Mean monthly base time minimum temperature and model error of the study area.

In most case the model prediction error for this study is acceptable for both temperature and rainfall data. Because, according to [9] model error value of $1^{\circ} \mathrm{C}$ for temperature and $0.8 \mathrm{~mm}$ for rainfall are tolerable. On the other hand, some months of the year for both RCP4.5 and RCP8.5 has high model prediction error for all water data. This may be creating uncertainty for future data estimation of this study for these months.

\subsection{Analysis of Observed and Downscaled Data}

\subsubsection{Observed and Future Precipitations}

The mean results of future precipitation, which was downscaled from canESM2 GCM by using NCEP-NCAR predictors show significant variation when it compared with the reference period (1976-2005), observed mean rainfall data in the study area for all rainfall season annual, Kiremt and Belg.

The mean value of rainfall during the Belge rain season in all future three time horizons (2020s, 2050s and 2080s) of this study (Table 2) will indicate a higher value than the base time mean value of Belg season rainfall for RCP4.5. However, for RCP8.5 the mean value of Belg rainfall will indict lower value as compared to observed time mean Belg rainfall value. The maximum increasing and decreasing mean 
value of Belg rainfall will occur in 2020s for RCP4.5 and RCP8.5 respectively.

Table 2. Mean of future Belg season rainfall relative to the base period.

\begin{tabular}{|c|c|c|c|c|c|c|}
\hline \multirow{2}{*}{ Observation } & \multicolumn{6}{|c|}{ Projected Belg rainfall (mm) } \\
\hline & RCP4.5 & & & RCP8.5 & & \\
\hline Base period & $2020 s$ & 2050s & $2080 s$ & $2020 \mathrm{~s}$ & $2050 \mathrm{~s}$ & $2080 s$ \\
\hline 42.13 & 45.29 & 43.29 & 43.22 & 38.10 & 38.74 & 38.85 \\
\hline Increase/Decrease (\%) & $7.5^{*}$ & 2.75 & 2.59 & $-9.57^{*}$ & -8.04 & -7.78 \\
\hline
\end{tabular}

*Maximum increase and decrease in 2020s, for RCP4.5 and RCP8.5, respectively 2020s (2006-2035), 2050s (2036-2065) and 2080s (2066-2095)

In the future relative to the observed mean value of Kiremt rainfall, for all future time intervals of this study, mean value of Kiremt rainfall will decrease for both RCP4.5 and RCP8.5 emission scenarios (Table 3). The maximum decreasing rate will occur in 2050 s for both RCP4.5 (16.75\%) and RCP8.5 (26.7\%). The decreasing rate of mean Kiremt season rainfall is higher for RCP8.5 relative to RCP4.5 in respective future time interval of this study. As cited by [10], Arndt et al. (2011) indicate that the future projections Kiremt rainfall will decline by $20 \%$ in Ethiopia and also [11] indicated that seasonally maximum precipitation reduction is projected during Ethiopian local rainy season of Kiremt in the future time horizons.

Table 3. Future mean Kiremt rainfall change relative to the base period rainfall.

\begin{tabular}{lcccccc}
\hline \multirow{2}{*}{ Observation } & \multicolumn{6}{l}{ Projected Kiremt rainfall $(\mathbf{m m})$} \\
\cline { 2 - 7 } & RCP4.5 & \multicolumn{4}{c}{ RCP8.5 } \\
\hline Base period & $\mathbf{2 0 2 0 s}$ & $\mathbf{2 0 5 0 s}$ & $\mathbf{2 0 8 0 s}$ & $\mathbf{2 0 2 0 s}$ & $\mathbf{2 0 5 0 s}$ & $\mathbf{2 0 8 0 s}$ \\
\hline 94.25 & 83.57 & 78.46 & 90.65 & 81.50 & 69.08 & 87.96 \\
Increase/Decrease (\%) & -11.33 & $-16.75 *$ & -3.82 & -13.52 & $-26.7 *$ & -6.69 \\
\hline
\end{tabular}

*Maximum decreasing in 2050s for both RCP4.5 and RCP8.5

Future expected mean annual rainfall in 2080s in the River catchment will show maximum decreased (13.8\%) mean annual rainfall value relative to observed mean annual rainfall (Table 4). In the River catchment RCP4.5 shows $7.03 \%$ and $1.36 \%$ decrement in the $2020 \mathrm{~s}$ and $2050 \mathrm{~s}$ respectively; RCP 8.5 also shows $5.47 \%$ and $7.22 \%$ decrement in the same respective time. This result is found in the same line with [12] all models and scenarios show a decrease in mean annual precipitation and consequently, a decrease in runoff in lower Awash River Basin, Projection of future mean annual rainfall conditions suggest that the annual mean rainfall in the Central Rift Valley area is most likely to decrease [11], the generated future scenarios results show decreasing trend for mean annual precipitation in upper Awash Sub-basin, of Ethiopia [13] and also as cited by [12], Monireh et al. (2013) was also indicated up to $25 \%$ decline of mean annual precipitation in Ethiopia for the future time interval. For all rain season in the River catchment the differences between the outputs of future mean rainfall of annual, Kiremt and Belg for RCP 4.5 and RCP 8.5 scenarios show highly decreased value for RCP 8.5 in the most future time interval.
Table 4. Future annual rain fall change relative the base time.

\begin{tabular}{lllllll}
\hline \multirow{2}{*}{ Observation } & \multicolumn{6}{l}{ Projected Annual rainfall (mm) } \\
\cline { 2 - 7 } & RCP4.5 & \multicolumn{5}{c}{ RCP8.5 } \\
\hline Base period & $\mathbf{2 0 2 0 s}$ & $\mathbf{2 0 5 0 s}$ & $\mathbf{2 0 8 0 s}$ & $\mathbf{2 0 2 0 s}$ & $\mathbf{2 0 5 0 s}$ & $\mathbf{2 0 8 0 s}$ \\
\hline 179.41 & 166.79 & 181.86 & 169.78 & 169.60 & 166.45 & 154.63 \\
Increase/Decrease & -7.03 & 1.36 & -5.37 & -5.47 & -7.22 & $-13.8 *$ \\
$(\%)$ & & & & & & \\
\hline
\end{tabular}

*Maximum decrease in $2080 \mathrm{~s}$, for RCP8.5

\subsubsection{Observed and Future Temperature}

Monthly maximum temperature, which expected in the 2020s for both RCP4.5 and RCP8.5 emission scenarios in Rive catchment, is shown in Figure 8. The Figure indicates that increment of monthly maximum temperature in both scenarios in most months of the year relative to the historical monthly maximum temperature. Since the two scenarios (RCP4.5 and RCP8.5) graphs are overlap together, it indicates that insignificant different between RCP4.5 and RCP8.5 scenario mean monthly maximum temperature. But, the expected mean annual maximum temperature increase by $2.15^{\circ} \mathrm{C}$ and $2.18^{\circ} \mathrm{C}$ in the River catchment relative to the, mean annual maximum temperature of historical time for RCP4.5 and RCP8.5 respectively. The future time Belg and Kiremt mean maximum temperature of the River catchment increased by $2.39^{\circ} \mathrm{C}$ for RCP4.5 and $2.41^{\circ} \mathrm{C}$ for RCP8.5 in Belg season and $0.67^{\circ} \mathrm{C}$ for RCP 4.5 and $0.75^{\circ} \mathrm{C}$ for RCP8.5 in Kiremt.

In the $2050 \mathrm{~s}$, the variation of expected mean maximum monthly temperature is different month to month for both RCP4.5 and RCP 8.5 emission scenarios. As shown in Figure 9, the expected mean monthly maximum temperature for RCP 4.5 is greater than the observed mean monthly maximum temperature throughout the whole months. Also, RCP8.5 shows higher mean monthly maximum temperature except for the months of June and July. In the months January to April and September to December the expected mean monthly maximum temperature is higher for RCP8.5 relative to RCP 4.5 . In the rest of the months, the maximum mean monthly temperature is greater for RCP 4.5. The maximum mean annual temperature of the River catchment will show $2.22^{\circ} \mathrm{C}$ and $2.24^{\circ} \mathrm{C}$ increment for $\mathrm{RCP} 4.5$ and RCP8.5 emission scenarios respectively when it compare to the historical maximum mean annual temperature of the River catchment in 2050s. 


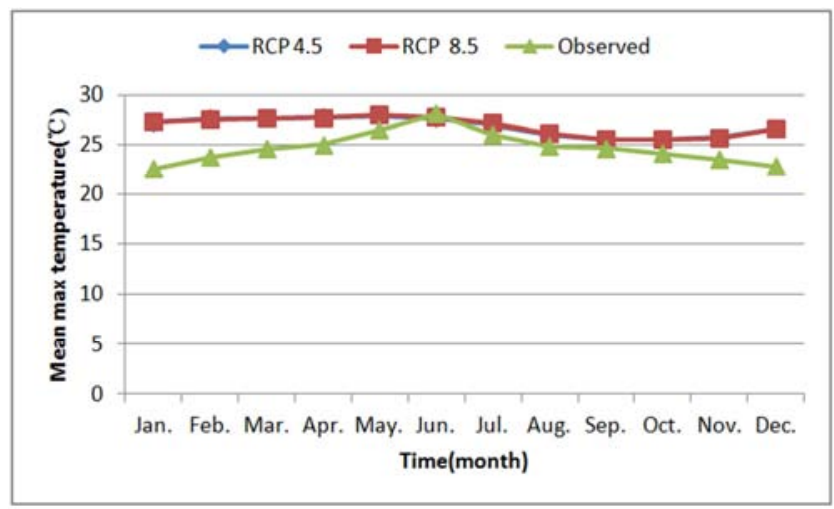

Figure 9. Observed and Future mean monthly maximum temperature in 2020 s.

In the $2050 \mathrm{~s}$, the mean maximum temperature of Belg season shows an increment relative to the historical Belg season mean maximum temperature $\left(1.06^{\circ} \mathrm{C}\right.$ for $\mathrm{RCP} 4.5$ and $1.14^{\circ} \mathrm{C}$ for RCP8.5). On the other hand, Kiremt season mean maximum temperature shows an increment for RCP4.5 $\left(1.81^{\circ} \mathrm{C}\right)$ and decrement value for $\operatorname{RCP} 8.5\left(0.1^{\circ} \mathrm{C}\right)$ emission scenarios.

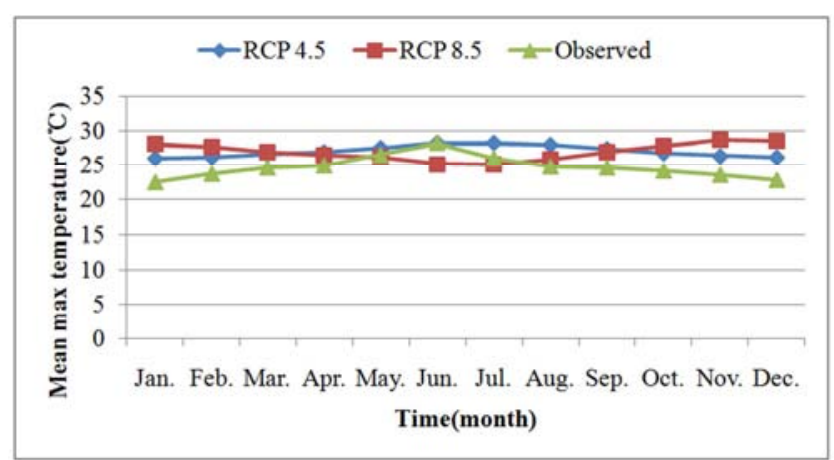

Figure 10. Observed and Futures mean monthly maximum temperature in 2050 s.

In the 2080s as shown in Figure 11, the expected mean maximum monthly temperature from the emission scenario of RCP4.5 and RCP 8.5 is higher than the historical mean monthly maximum temperature of the study area. In the month January-May, the maximum mean monthly temperature of the River catchment for RCP4.5 and RCP8.5 has no significant difference. But from the month JuneDecember, the mean monthly maximum temperature for RCP8.5 is higher than that of RCP4.5 emission scenario.

In the $2080 \mathrm{~s}$, the mean annual maximum temperature of the River catchment will be increased by $1.98^{\circ} \mathrm{C}$ for RCP4.5 and $2.82^{\circ} \mathrm{C}$ for RCP 8.5 as compared to the historical mean annual maximum temperature of the study area. Relative to the historical maximum temperature the future maximum temperature will increase by $1.63^{\circ} \mathrm{C}$ for RCP4.5 and $1.67^{\circ} \mathrm{C}$ for RCP8.5 in Belg season; $1.32^{\circ} \mathrm{C}$ for RCP4.5 and $3.1^{\circ} \mathrm{C}$ for RCP8.5 in Kiremt season in the River catchment in 2080s. And also relative to other time intervals (2020s, 2050s) maximum temperature increment $\left(3.1^{\circ} \mathrm{C}\right)$ will expected in 2080s for RCP8.5 in Kiremt season.

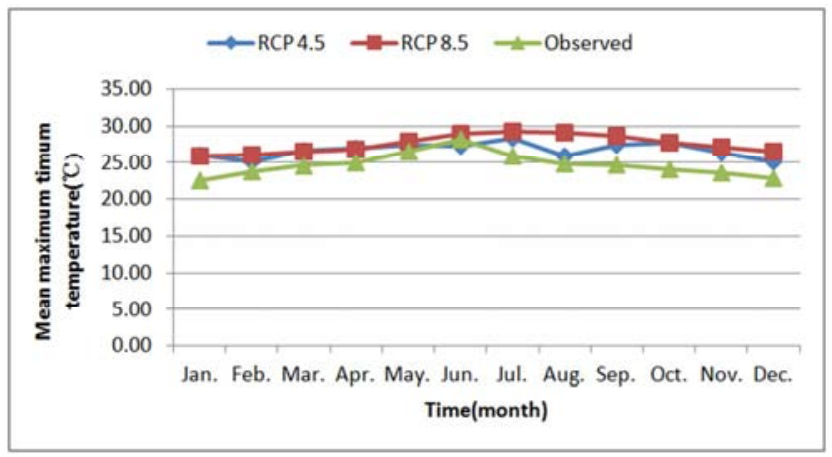

Figure 11. Observed and Future monthly maximum temperature in 2080 s.

The mean monthly minimum temperature of Borikena River catchment for the time interval of the 2020s, 2050s and 2080s were shown in Figure 12 up to Figure 14 respectively. In 2020 s the RCP8.5 emission scenario indicates higher value of mean monthly minimum temperature than the RCP4.5 emission scenario and observed mean monthly minimum temperature in most months. On the other hand, when it is compared with the observed mean monthly minimum temperature, RCP4.5 emission scenario shows lower value of mean monthly minimum temperature from the month January- September.

In the 2020s relative to historical mean annual minimum temperature of Borikena River catchment the expected mean annual minimum temperature increased by $0.13{ }^{\circ} \mathrm{C}$ for $\mathrm{RCP} 4.5$ and $1.85^{\circ} \mathrm{C}$ for RCP8.5; for RCP4.5 the mean minimum temperature of the River catchment in both Belge and Kiremt season will be decreased by $0.61^{\circ} \mathrm{C}$ and $0.65^{\circ} \mathrm{C}$ relative to the historical time Belge and Kiremt mean minimum temperature, respectively. On the other hand, for RCP8.5 both Belge and Kiremt season' mean minimum temperature will be increased by $0.99{ }^{\circ} \mathrm{C}$ and $1.29^{\circ} \mathrm{C}$ respectively.

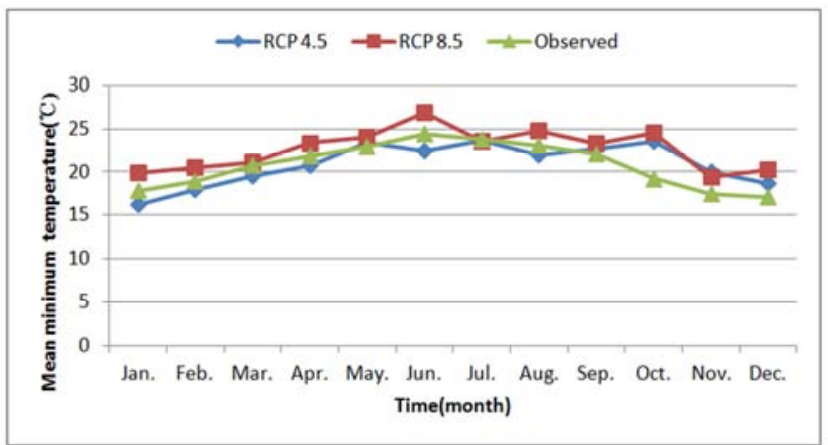

Figure 12. Observed and Futures mean monthly minimum temperature in 2020 s.

In 2050s (Figure 13) without the month July and August the expected mean monthly minimum temperature for $\mathrm{RCP} 8.5$ is higher than that of RCP4.5 and also it is higher than observed mean monthly minimum temperature in all months of the year. At the same time interval from the month January- October the mean minimum temperature for RCP4.5 do not show much different from the observed mean 
minimum temperature. However, in this time interval (2050s) the mean annual, Belg and Kiremt season minimum temperature of the River catchment will show variations when it compares to the historical time mean annual, Belg and Kiremt. For both emission scenarios of RCP4.5 and RCP8.5 the mean annual minimum temperature of the study area will increase by $0.33^{\circ} \mathrm{C}$ and $1.19^{\circ} \mathrm{C}$ respectively. The mean minimum temperature decrement will be expected in $2050 \mathrm{~s}$ in the River catchment with a value of $0.39^{\circ} \mathrm{C}$ in Kiremt and $0.15^{\circ} \mathrm{C}$ in Belg for RCP4.5. On the other hand, both Belge and Kiremt will increase by $0.82^{\circ} \mathrm{C}$ and $0.17^{\circ} \mathrm{C}$ for RCP8.5 emission scenarios respectively.

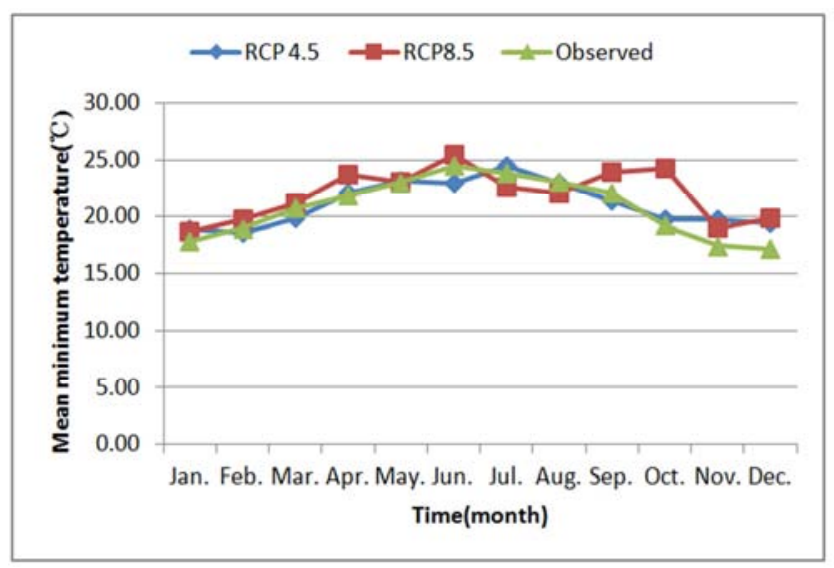

Figure 13. Observed and Futures mean monthly minimum temperature in 2050 s.

For both RCP4.5 and RCP8.5 mean monthly minimum temperature show increment value in the whole month in 2080s (Figure 14) as they compare with historical mean monthly minimum temperature. In this period (2080s) the months January-March have all most similar increment for both RCP4.5 and RCP8.5. But from the month Jun-August RCP4.5 shows a higher increment than RCP8.5.

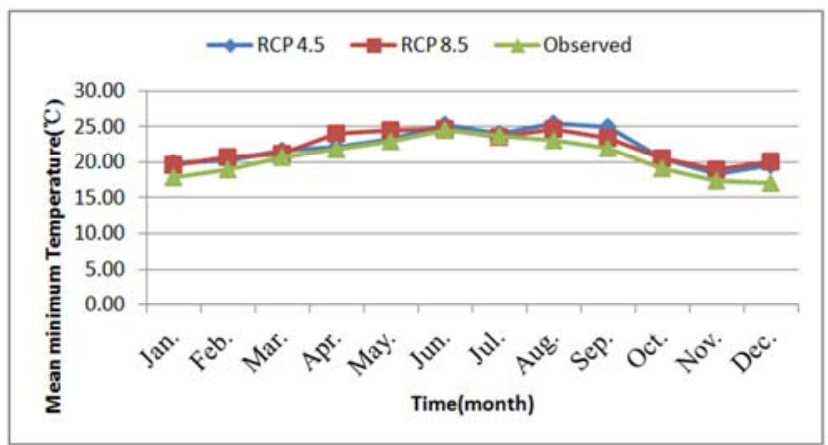

Figure 14. Observed Futures mean monthly minimum temperature in 2080 s.

The expected mean annual minimum temperature of the River catchment also will increase by $1.35^{\circ} \mathrm{C}$ for RCP4.5 and $1.37^{\circ} \mathrm{C}$ for $\mathrm{RCP} 8.5$ in $2080 \mathrm{~s}$ when it compared to the historical mean annual minimum temperature. Similar nature with future mean annual minimum temperature in $2080 \mathrm{~s}$ Belge and Kiremt season mean minimum temperature in the 2080s expected by the increment value for both RCP4.5 and
RCP8.5 emission scenarios. In Belge the increment value for RCP8.5 $\left(1.34^{\circ} \mathrm{C}\right)$ will higher than that of RCP4.5 $\left(0.51^{\circ} \mathrm{C}\right)$; the condition will reverse in Kiremt when the mean minimum temperature will increase by $1.61^{\circ} \mathrm{C}$ and $0.73^{\circ} \mathrm{C}$ for RCP 4.5 and RCP8.5 respectively.

\section{Conclusion and Recommendation}

In this study Statistical Downscaling Method (SDSM) was able to simulate climatic events from selected predictor variables. The simulated results of SDSM for this study showed that the method was able to simulate the climatic variables (precipitation and temperature) which follow the same trend with the observed one in the most future time horizon of this study. However, due to its conditional process, high spatial and temporal variability nature of precipitation shows some variation in each station in some months of the year, but the overall result from SDSM in the whole River catchment was well correlated with the observed precipitations. So by considering the present predictor predictand relationship is unchanged in the River catchment for the future climate conditions SDSM can predict the future climatic events conditions for the analysis of any activity related to climate change for this study. The result of future temperature from SDSM for RCP4.5 and RCP8.5 show increased rate for both maximum and minimum temperature on annual basis except 202s for RCP4.5. The maximum increasing value will occur for RCP8.5 in the 2020s and $2080 \mathrm{~s}$ with a value of $1.85^{\circ} \mathrm{C}$ and $2.82^{\circ} \mathrm{C}$ for minimum and maximum temperature respectively. Similar to annual future maximum temperature, the future maximum temperature of the River catchment in Belg and Kiremt season will show increasing rate for both RCP4.5 and RCP8.5 emission scenarios without 2050s Kiremt season maximum temperature for $\mathrm{RCP} 8.5$ which will indicate $0.15^{\circ} \mathrm{C}$ of decreased value relative to the observed maximum temperature. The maximum increasing for Kiremt and Belg season will occur in the 2080s and 2020s for RCP8.5 with a value of $3.1^{\circ} \mathrm{C}$ and $2.41^{\circ} \mathrm{C}$. In the River catchment future monthly maximum and minimum temperature for Belg and Kiremt season do not show a systematic increasing or decreasing value for the future three time horizons.

The results of downscaled precipitation for future time interval of this study indicate decreased precipitation value for both RCP4.5 and RCP8.5 on annual basis. This will be due to the reason that for both scenarios Kiremt rainfalls which is the main source of rainfall for the River catchment will decrease in the next three time horizon of this study with a maximum value of $26.71 \%$ in the $2050 \mathrm{~s}$ for RCP8.5 emission scenarios. The minor rain source of the River catchment which is called Belg, will increase for RCP4.5 and decrease for RCP8.5 in all three time horizons with a maximum value of $7.5 \%$ and $9.57 \%$ in the $2020 \mathrm{~s}$ respectively.

Therefore, this facilitate the decision makers to incorporate climate change scenarios for devising sustainable strategies, including: Water harvesting technologies, supplementary 
irrigation, using improved seeds, which can tolerate moisture stresses, afforestation and reforestation programs, and soil and water conservation techniques. Moreover, crop diversifications, agricultural extension services access, related strategies, and measures are highly recommended for climate change resiliencies in the study area.

\section{References}

[1] Abbasnia, M., \& Toros, H. 2016. Future changes in maximum temperature using the statistical downscaling model (SDSM) at selected stations of Iran. Modeling Earth Systems and Environment, 2 (2). https://doi.org/10.1007/s40808-016-0112$\mathrm{z}$.

[2] No, R. S., Scandinavian, S., Network, N. E., \& Bases, T. F. (2003). Climate Change Scenarios for the SCANNET Region. (4663).

[3] Intergovernmental Panel on Climate Change (IPCC).2012. Managing the Risks of Extreme Events and Disasters to Advance Climate Change Adaptation: Special Report of the Intergovernmental Panel on Climate Change; Cambridge University Press: New York, NY, USA.

[4] Wilby, R. L.; Wigley, T. 1997. Downscaling general circulation model output: A review of methods and limitations. Prog. Phys. Geogr. 21, 530-548. [CrossRef].

[5] Legesse, S. A., Rao, P. V. V. P., \& Rao, M. M. N. 2013. Statistical Downscaling of Daily Temperature and Rainfall Data From Global Circulation Models : in South Wollo Zone, North Central Ethiopia. National Monthly Referred Journal of Research in Science \& Technology, 2 (7), 27-39.

[6] Ayalew, D., Tesfaye, K., Mamo, G., Yitaferu, B., \& Bayu, W.
2012. Outlook of future climate in northwestern Ethiopia. 3 (4), 608-624.

[7] Worqlul, A. W., Dile, Y. T., Ayana, E. K., \& Jeong, J. 2018. Impact of Climate Change on Streamflow Hydrology in Headwater Catchments of the Upper Blue Nile. https://doi.org/10.3390/w10020120

[8] Dawson, C. W., Abrahart, R. J. and See, L. M., 2007. HydroTest: a web-based toolbox of evaluation metrics for the standardised assessment of hydrological forecasts. Environmental Modelling \& Software, 22 (7), pp. 1034-1052.

[9] Schmidli, J., Frei, C., \& Vidale, P. L. 2006. Downscaling from GCM precipitation: A benchmark for dynamical and statistical downscaling methods. International Journal of Climatology, 26 (5), 679-689. https://doi.org/10.1002/joc.1287

[10] Daba, M. H., Tadele, K., Shimelis, A., \& Melesse, A. M. 2017. Hydrological Response to Climate Change Impacts and Adaptation Strategies for Upper Awash Sub-basin, in the Awash Basin, Ethiopia Director General, Transport Construction Design S. Company, Addis Ababa, Ethiopia Biometrics, GIS and Agro meteorology. (October). https://doi.org/10.1007/978-94-007-0689-7

[11] Kassie, B. T., Pioneer, D., Hengsdijk, H., \& Asseng, S. (2013). Climate variability and change in the Central Rift Valley of Ethiopia: Challenges for rainfed crop production Climate variability and change in the Central Rift Valley of Ethiopia: challenges for rainfed crop production. (June 2016). https://doi.org/10.1017/S0021859612000986

[12] Abraham, T. 2018. Impacts of Climate Change Under CMIP5 $R C P$ Scenarios on the Hydrology of Lake Ziway Catchment, Central Rift Valley of. 8 (7).

[13] Asore, D. G., Nour, M. H., Zaghloul, A. S., \& Hamed, K. H. 2010. impact of climate change on evapotranspiration and runoff in awash basin. 